\title{
Farklı eğe sistemlerinin kök kanallarından kalsiyum hidroksiti uzaklaştırmadaki etkinliklerinin değerlendirilmesi ${ }^{*}$
}

\author{
Selen İnce Yusufoğluํ․ Mine Özçelik ${ }^{1}$, Hale Arı Aydınbelge ${ }^{1}$
}

Selcuk Dental Journal, 2015; 3: 122-129

Başvuru Tarihi: 09 Haziran 2015 Yayına Kabul Tarihi: 17 Aralık 2015

\section{ABSTRACT \\ Evaluation of different file systems on the removal of calcium hydroxide paste from the root canals}

Background: To evaluate the efficacy of different file systems on the removal of calcium hydroxide paste from single rooted teeth.

Methods: Thirty single rooted teeth were used. The root canals were shaped with ProTaper Universal F4 files. Calcium hydroxide paste was placed into each root canals, and packed to the working length. Then cotton pellets were placed over the canal orifices and coronal parts of the roots were sealed with cavit. Specimens were stored in distilled water for 7 days at $37^{\circ} \mathrm{C}$. After 7 days the temporary coronal seal was removed and the samples were randomly divided into four experimental groups (ProTaper Universal F4, ProTaper Next X4, Wave One Large, Resiproc 40) $(n=12)$ and a control group (only irrigated with $\mathrm{NaOCl})(n=12)$ according to the method used for calcium hydroxide paste removal. The roots were split longitudinally into halves (60 specimens) and the both canals examined using a stereomicroscope. The amount of remaining calcium hydroxide paste in the canal walls were measured under a stereomicroscope at $\times 15$ magnification. The data were statistically analysed using Cronbach's alpha tests at a significance level of $p<0.05$.

Results: It was not possible completely to remove $\mathrm{Ca}(\mathrm{OH})_{2}$ paste from root canals. Reciproc 40 files removed significantly more $\mathrm{Ca}(\mathrm{OH}) 2$ paste than the other groups (Wave One Large, ProTaper Universal F4, ProTaper Next $\mathrm{X} 4$, and control groups) $(p<0.05)$. Control group removed less $\mathrm{Ca}(\mathrm{OH})_{2}$ than the other experimental groups but this was not statistically significant $(p>0.05)$.

Conclusion: Reciproc instrumentation technique with $\mathrm{NaOCl}$ were more effective in removing $\mathrm{Ca}(\mathrm{OH})_{2}$ from canals than only $\mathrm{NaOCl}$ irrigation and Wave One, ProTaper Universal, ProTaper Next instrumentation tecniques. But none of used file systems completely to remove $\mathrm{Ca}(\mathrm{OH})_{2}$ paste from root canals.

\section{KEYWORDS}

Protaper next, protaper universal, removal of $\mathrm{Ch}$, resiproc, waveone
Kök kanalından mikroorganizmaların eliminasyonu endodontik tedavinin temel amaçlarından biridir (Bystrom \& Sundqvist, 1981). Mevcut enstrümantasyon teknikleri arasında hiçbiri tamamen temizlenmiş kök kanal sistemi elde edememektedir (Hülsmann ve ark, 2005). Bu nedenle kök kanal ilaçlarının kullanımı dezenfeksiyonu artırmak için kullanılmaktadır (Bystrom ve ark 1985, Grecca ve ark 2001, Tanomaru-Filho ve ark 2002). En yaygın olarak kullanılan kök kanal ilacı, endodontik patojenlerin çoğunluğuna karşı antibakteriyel etkisinden (Siqueira ve Lopes, 1999) ve biyouyumluluğundan (Athanassiadis, 2007) dolayı kalsiyum hidroksittir $(\mathrm{KH})$. KH'in apeksifikasyonun uyarımasında, periapikal lezyonlu nekrotik dişlerde ve iç ve dış kök rezorbsiyonlarının kontrol edilmesinde kullanılması önerilmektedir (Ayna ve ark 2010, Faria ve ark 2004, Faria ve ark 2005, Mohammadi ve Dummer, 2011). Uygun bir taşıyıcı ile karıştıılarak kök kanalı içerisinde birkaç gün veya hafta bırakılması yaygın endodontik tedavide kabul edilen bir uygulamadır (Fava ve Saunders 1999, Lee ve ark 2009).

Kök kanal dolgusundan önce kanala yerleştirilen KH'in kaldırıması gerekmektedir. Dentin yüzeyindeki $\mathrm{KH}$ kalıntıları kök kanal dolgusunun kalitesini negatif olarak etkilemekte (Çalışkan ve ark 1998, Barbizam ve ark 2008), dentin tübülleri içerisine patların penetrasyonunu önlemekte ve apikal

\footnotetext{
* 17. Biennial ESE Kongresi-Barselona/İSPANYA , 15.09.2015

${ }^{1}$ Selçuk Üniversitesi Diş Hekimliği Fakültesi Endodonti Anabilim Dalı, Konya
} 
sızıntıyı arttırabilmektedir (Kim ve Kim 2002).

KH'in kaldırımasında en çok kullanılan yöntem çalışma boyundaki ana apikal eğe kullanılarak $\mathrm{NaOCl}$ ve EDTA solüsyonlarının ajitasyonu ile irrigasyon yapmaktır (Lambrianidis ve ark 1999, 2006, Salgado ve ark 2009). Ayrıca, döner aletler (Kenee ve ark 2006, Kuga ve ark 2010), sonikultrasonik aktive edilmiş uçlar (Balvedi ve ark 2010, Wiseman ve ark 2011), ve irrigasyon solüsyonlarının aktivasyonunu artıran cihazlar (Van derSluis ve ark 2007) önerilmektedir. Bu yöntemlerin hiçbiri yine de kök kanallarından özellikle apikal üçlüden $\mathrm{KH}$ 'i tamamen uzaklaştırmada yeterli değildir (Balvedi ve ark 2010, Kenee ve ark 2006).

ProTaper Universal (PTU) (Dentsply, Maillefer, Ballaigues İsviçre) eğe sistemi Dr. Cliff Ruddle, Dr.John West ve Dr.Pierre Machtou tarafindan dizayn edilmiştir. Pro Taper eğeleri üstün esnekliği sağlamak, eşsiz verimlilik ve daha fazla güvenlik için özel olarak tasarlanmıştır (Cohen ve Burns, 2010). PTU eğelerinin enine kesiti keskin kesici kenarları ile birlikte modifiye K-tipi eğelere benzemektedir ve radyal alanları yoktur. Dışbükey üçgen kesitleri dentin ile eğe arasındaki temas alanını azaltmaktadır (Cohen ve Burns, 2010 ).

PTU sistemi üç tane şekillendirici, üç tane tamamlayıcı eğeden oluşmaktadır. Üç şekillendirici eğe; yardımcı şekillendirici SX, şekillendirici 1 S1, şekillendirici 2 S2'dir. Bunlar koronal kısmın genişletmesi içindir ve crown down tekniği ile kullanılırlar. İleri şekillendirme üç bitirme eğesi kullanılarak yapılır (F1-F2-F3) (Vaudt ve ark 2007). PTU eğeleri, $21 \mathrm{~mm}$ ve $25 \mathrm{~mm}$ ve $31 \mathrm{~mm}$ uzunluğunda bulunabilmektedirler (Ruddle, 2001). 2006 yllında PTU iki yeni bitirme eğesi eklenerek tanıtılmıştır; F4 (ISO 40) ve F5 (ISO 50) apikal preparasyon için geliştirilmiştir (Vaudt ve ark 2007).

ProTaper Next (PTN) (Dentsply, Maillefer, Ballagues, İsviçre) eğeleri üretici tarafından talep edildiği gibi merkezden uzak (off- centered), dikdörtgen geometrik kesitli olarak tasarlanmıştır. $\mathrm{Bu}$ kesit rotasyon esnasında artıkların taşınması için daha geniş bir alan oluşturur. Eğelerin esnekliğini ve yorulma dayanımlarını artırmak için M-Wire NiTi kullanılarak üretilmişlerdir. M-Wire NiTi materyali, kesme etkinliğini korurken eğe elastikiyetinide arttırır (Dentsply Maillefer, 2013). Kırıma riski önemli ölçüde azalmakta ve aynı zamanda orijinal kök kanal anatomisine uyum büyük ölçüde artmaktadır. Daha az eğe sayısı ve bütün eğeler için sadece bir tork ve hız ayarının olması süreyi kısaltmaktadır. Yüksek kesme etkinliği şekillendirme zamanını kısaltmaktadır (Dentsply Maillefer, 2013).
PTN eğeleri 5 boyutta bulunmaktadır: X1, X2, X3, X4, X5. PTN eğeleri de 21-25-31 $\mathrm{mm}$ uzunluğunda bulunabilmektedir (Dentsplay Maillefer, 2013).

Resiprokal hareketlerle kullanılan tek eğeli sistemler Resiproc (R) (VDW, Munih, Almanya) ve Wave One (WO) (Dentsply, Maillefer, İsviçre) preparasyon adımlarının azaltılması ve etkili bir endodontik tedavinin yapılması amacıyla ortaya çıkmıştır. İiside M-wire alaşımından yapılmıştır. Bu sistemler balanced force tekniği ile kullanılırlar (Amaral ve ark 2013). Resiprokal harekette birbirini izleyen saat yönünde ve saat yönünün tersine dönüş vardır. Bu hareket rotasyonal harekete göre yorgunluğu azaltmaktadır (You ve ark 2010).

Wave One sistemi tek kullanımlık, tek eğe sistemidir ve kanalı tamamen başlangıçtan bitişe kadar şekillendirir (Webber ve ark, 2011). Wave One Small, Wave One Primary ve Wave One Large olmak üzere üç farklı boyutta eğeler mevcuttur (Webber ve ark, 2011). Özel olarak tasarlanmış $\mathrm{NiTi}$ eğeleri balanced force hareketinin tersi şekilde resiprokal hareketlerle çalışır. Eğeler M-Wire teknolojisi kullanılarak üretilmiştir, gücünü ve yorgunluğa direncini diğer NiTi eğelere göre 4 kat artırmıştır (Johnson ve ark 2008). Şu anda 21, 25 ve 31 $\mathrm{mm}$ uzunluklarında Wave One tek eğe sistemi mevcuttur (Webber ve ark 2011).

Wave One eğeleri çeşitli kesitlere sahiptir, uç kısmında içbükey üçgen kesiti ve radyal alanı vardır, şaft kısmına yakın ve orta kısmında dışbükey üçgen kesite sahiptir ve negatif rake açısı vardır (Bürklein ve ark 2012). Resiprokal hareketlerle kombine radyal alanlar Wave One eğelerini apikale doğru ilerlerken merkezde tutmayı sağlar (Webber ve ark 2011).

Reciproc eğe sistemi tek bir alet olarak kullanılmak üzere tasarlanmıştır. Kök kanalını hazırlamak için sadece bir alete gerek duymaktadır. Resiproc aleti ile elde edilen şekil sıcak ve soğuk tekniklerle etkili şekilde tıkamaya, irrigasyona olanak sağlar (VDW, 2014). Resiproc eğeleri uç boyutlarına göre R25, R40 ve R50 olarak bulunmaktadır, renkleri srasıyla kırmızı, siyah ve sarıdır (VDW, 2014).

Reciproc eğeleri iki keskin kesme kenarı ile beraber $\mathrm{S}$ şekilli enine kesite sahiptir. Eğelerin $S$ şekilli kesitlere sahip olması tamamen saat yönünde rotasyonda kullanılmalarında nispeten daha iyi şekillendirme kabiliyeti sağlar (Bürklein ve ark 2012). Reciproc eğeleri de M-Wire NiTi aletlerden üretilmiştir, bu sayede kırıklara direnci artmıştır ve yüksek elastisiteye sahiptir. Aletler steril edilip paketlenmiştir ve tek kullanımdan sonra atılır bu sayede çapraz enfeksiyondan korunulur, dar ve kurvatürlü kanallarında preparasyonu için uygundur (VDW, 2014).

$\mathrm{Bu}$ çalışmanın amacı farklı eğe sistemlerinin kök kanallarından $\mathrm{KH}$ 'i uzaklaştııımasındaki etkinliğini stereo mikroskop altında incelemektir. 


\section{GEREÇ VE YÖNTEM}

Çalışmada periodontal veya ortodontik nedenlerle çekilmiş 30 adet tek köklü alt premolar insan dişi kullanıldı. Dișler \%5'lik $\mathrm{NaOCl}$ ile dezenfekte edildikten sonra çalışmada kullanilıncaya kadar distile su içerisinde bekletildi. Dişlerin kuronları minesement sınırından düşük hızla dönen elmas separe kullanılarak ayrıldı ve uzunluğu $13 \mathrm{~mm}$ olan standart kökler elde edildi. Kök yüzeyinde kırık, çürük, çatlak ve deformite olan dişler çalışmaya dahil edilmedi. Pulpa dokusu çıkarıldıktan sonra kök kanalları F4 nolu ProTaper eğesi ile şekillendirildi. Preparasyon sırasında kök kanallarının irrigasyonunda $2 \mathrm{~mL} \% 2.5 \mathrm{NaOCl}$ solüsyonu kullanıldı. Preparasyon sonrası son irrigasyon olarak, $2 \mathrm{~mL} \% 2.5 \mathrm{NaOCl}, 2 \mathrm{~mL} \% 17$ EDTA ve $2 \mathrm{~mL}$ distile su kullanıldı ve kökler kağıt konlar ile kurulandı. $\mathrm{KH}$ gliserin ve su ile karıştırılarak bir lentulo vasıtası ile bütün kök kanallarına yerleştirildi. Kökün koronal kısımları pamuk ve geçici bir dolgu maddesi ile (Cavit; 3M, ESPE, St.Paul, USA) kapatılı. Örnekler distile su içerisinde $370 \mathrm{C}^{\prime} \mathrm{de} 1$ hafta süreyle bekletildi. Beklemeden sonra örneklerin koronalindeki geçici dolgu kaldırıldı. Kök kanalı içerisindeki $\mathrm{KH}^{\prime}$ 'in uzaklaştııımasındaki kullanılan yönteme göre örnekler rastgele 5 gruba ayrıldı $(n=12)$. Gruplar aşağıdaki gibi sınıflandırıldı.

Kontrol Grubu: Sadece \%5' lik $\mathrm{NaOCl}$ kullanıldı.

ProTaper Universal: F4 nolu ProTaper eğesi kullanıldı.

ProTaper Next: X4 nolu ProTaper Next eğesi kullanıldı.

Reciproc: R40 nolu Reciproc eğesi kullanıldı.

WaveOne: WaveOne Large 40 nolu eğesi kullanıldı.

Eğe kullanılan grupların irigasyonunda eğelemeden önce $5 \mathrm{~mL}$ ve eğelemeden sonra $5 \mathrm{~mL}$ olmak üzere toplam $10 \mathrm{~mL} \% 5^{\prime}$ lik $\mathrm{NaOCl}$ kullanıldı. Kontrol grubunda ise eğeleme yapılmadan sadece $10 \mathrm{~mL} \% 5$ ' lik $\mathrm{NaOCl}$ kullanıldı. İrigasyon iğnesi kök boyunun 2/3' üne yerleştirilerek irigasyon gerçekleştirildi. İigasyondan sonra kök kanalları kağıt konlar ile kurulandı. Daha sonra köklerin bukkal ve lingual dış yüzeylerine uzunlamasına elmas separe ile kuru ortamda iç tabakaya zarar vermeden çentik açıldı. Çentik açılan bölgelere siman spatülü yerleştirilerek kök bukko-lingual olarak ikiye ayrıldı.
Kök kanallarının iç yüzeyleri stereomikroskop ile $\times 15$ büyütmede iki araştırıcı tarafından incelendi. Kanal duvarlarında kalan $\mathrm{KH}$ miktarının sınıflandırımasında Faria ve ark (2013) tarafından yapılan skorlamaya benzer bir skorlama sistemi kullanıldı.

(1) Kanal duvarlarında hiç veya çok az KH bulunması,

(2) Kanal duvarlarında küçük KH birikintileri bulunması,

(3) Kanal duvarlarında birçok miktarda ancak duvarlarının \% 50 sinden daha azının $\mathrm{KH}$ ile kaplı olması,

(4) Kanal duvarlarının \% 50' sinden daha fazlasının $\mathrm{KH}$ ile kaplı olması,

(5) Kanal duvarlarının tamamının veya tamamına yakınının $\mathrm{KH}$ ile kaplı olması.

Verilerin istatistiksel analizi SPSS (Sta $\neg$ tistical Package for Social Sciences, version 11.5, SPSS Inc., Chicago, IL, ABD) programı ile gerçekleştirildi. İstatistiksel analizde Cronbach's alfa yönteminde $\mathrm{P}<0,05$ için sonuçlar anlamlı kabul edildi.

\section{BULGULAR}

Hiç bir eğe sisteminin KH'i kanal duvarlarından tamamen uzaklaştırdığı görülmemiştir. Kanal duvarlarında kalan $\mathrm{KH}$ miktarının sınıflandırımasında kullanılan skorlama sisteminde örneklerin skor 5 sınıfına dahil olmadığı belirlenmiştir. Çalışmadan elde edilen skor 1, skor 2 ve skor 3' e ait örnek stereomikroskop görüntüleri Şekil 1, Şekil 2, Şekil 3, Şekil 4, Şekil 5'de gösterilmiştir. Reciproc eğesinin WaveOne, ProTaper Next, ProTaper Universal ve kontrol grubuna göre kanal duvarlarından kaldırdığı KH miktarı daha fazla bulunmuştur $(P<0.05)$. Kontrol grubunun kanal duvarlarından daha az $\mathrm{KH}$ kaldırdığı görülmüş olup fakat istatistiksel olarak diğer gruplarla aralarında anlamlı bir fark bulunmamıştır $(P>0.05)$ (Tablo 1).

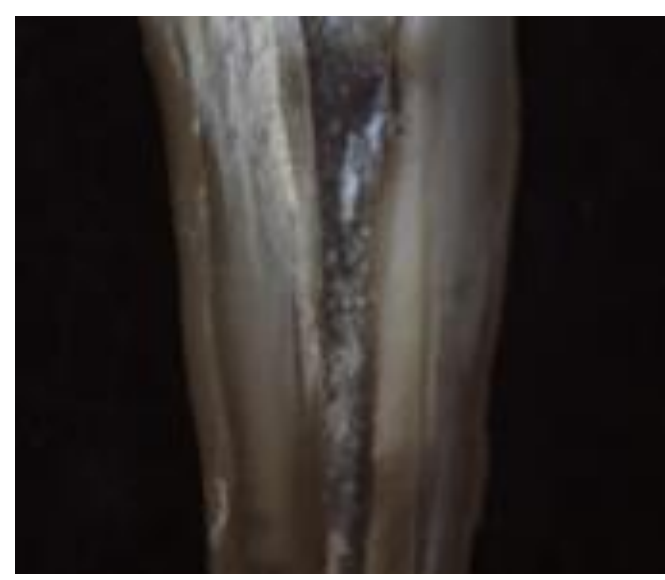

Şekil 1.

Kontrol Grubuna ait bir örneğin stereomikroskop görüntüsü, Skor 3 


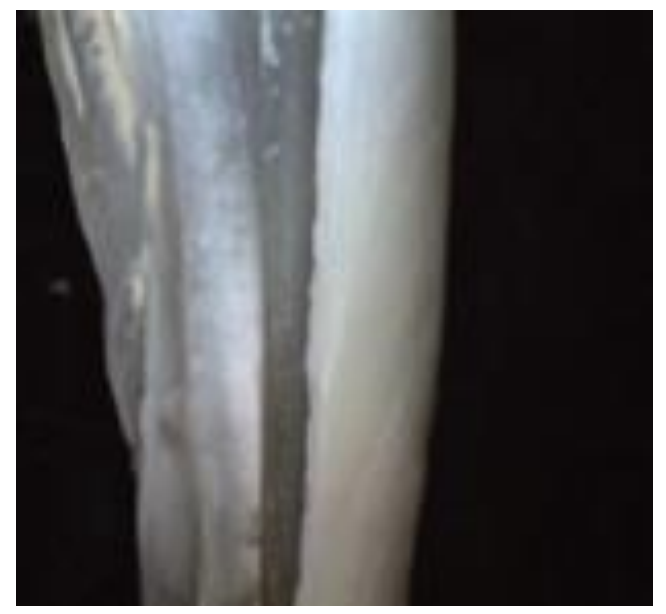

Şekil 2.

ProTaper Universal grubuna ait bir örneğin stereomikroskop görüntüsü, Skor 1

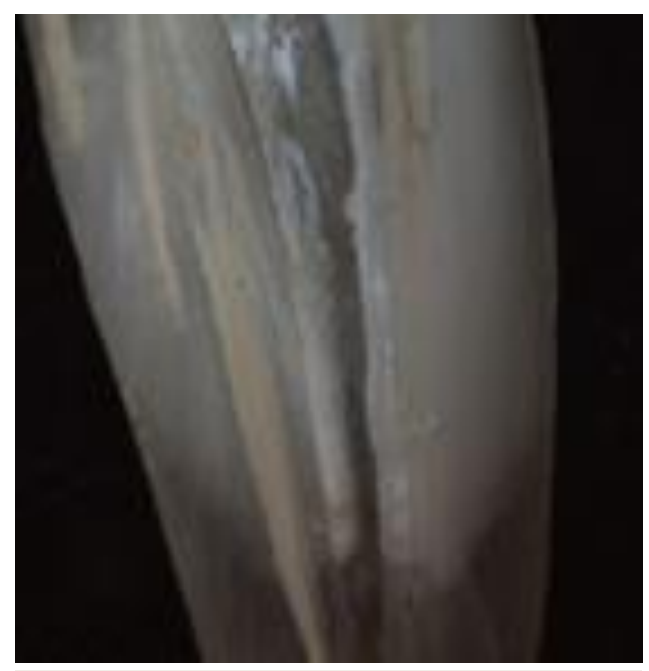

Şekil 3.

ProTaper Next grubuna ait bir örneğin stereomikroskop görüntüsü, Skor 2

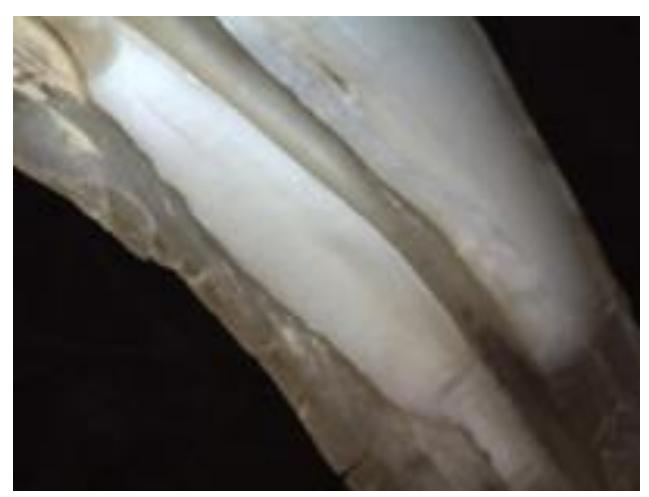

Şekil 4.

Resiproc grubuna ait bir örneğin stereomikroskop görüntüsü, Skor 1

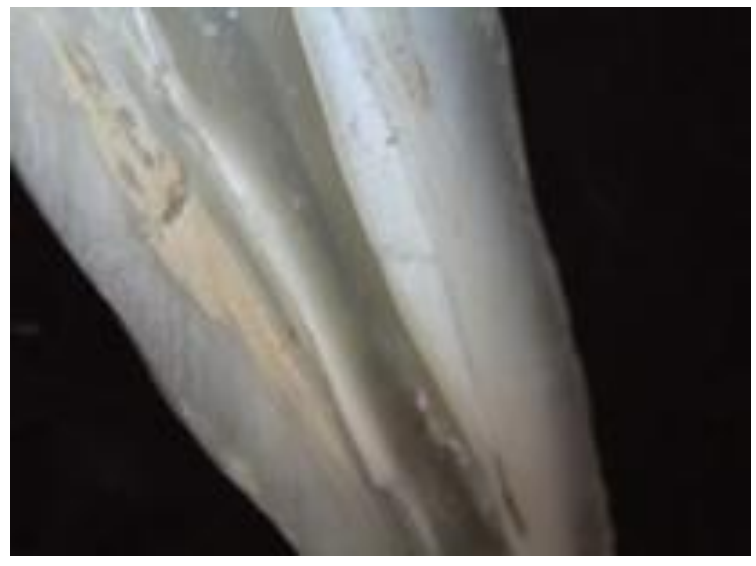

Şekil 5.

WaveOne grubuna ait bir örneğin stereomikroskop görüntüsü, Skor 1

Tablo 1.

\section{Grupların ortalama ve standart sapma değerleri}

\begin{tabular}{|lccccc|}
\hline Variable & N & Mean \pm SE Mean & StDev & Minimum & Maximum \\
\hline ProTaper Universal & 12 & $1.833 \pm 0.271^{\mathrm{a}}$ & 0.937 & 1000 & 4000 \\
\hline ProTaper Next & 12 & $1.750 \pm 0.218^{\mathrm{a}}$ & 0.754 & 1000 & 3000 \\
\hline Waveone & 12 & $2.083 \pm 0.288^{\mathrm{a}}$ & 0.996 & 1000 & 4000 \\
\hline Reciproc & 12 & $1.667 \pm 0.188^{\mathrm{b}}$ & 0.651 & 1000 & 3000 \\
\hline Kontrol & 12 & $2.500 \pm 0.230^{\mathrm{a}}$ & 0.798 & 1000 & 3000 \\
\hline
\end{tabular}

\section{TARTIŞMA}

Kanal içi ilaç olarak KH'in kullanılması mekanik enstrümantasyonun yanında doku çözücü etkisinden dolayı etkili bir yardımcıdır (Meire ve De Moor, 2008). Yine de, KH'in bazı vaka raporlarda kanal ramifikasyonlarındaki bakterileri uzaklaştırmada yavaş çözünürlüğünden ve dentin, doku sıvısı ve organik maddelerin varlığında inaktive olmasından dolayı yetersiz olduğu gösterilmiştir (Ricucci ve Siquera 2008 a,b). KH'in kanal duvarlarındaki varlığı endodontik tedaviyi olumsuz etkilemektedir (Ricucci ve ark 1997, Margelos ve ark 1997). KH artıklarının çinko oksit öjenollü patlarla etkileşerek kalsiyum öjenolat oluşturduğu bildirilmiştir (Margelos ve ark 1997). Ayrıca kök kanal duvarlarına patların adhezyonunu da etkilemektedir (Calt ve Serper 1999).

Calt ve Serper (1999) KH'i yalnızca NaOCl ile irigasyon yaparak tamamen uzaklaştırılamayacağını $\mathrm{NaOCl}$ ile beraber EDTA kullanarak kök kanal duvarlarından partiküllerinin tamamen uzaklaştırılığını bildirmiştir. Aynı şekilde Margelos ve arkadaşları (1997) \%15 EDTA veya NaOCl'nin yalnız kullanılmasıyla KH'in tamamen uzaklaştırılamayacağını, ikisinin beraber kombine kullanılmasında etkinliğin artacağını bildirmiştir. Lee ve ark (2004) irrigasyon tekniklerinin temizleme etkinliklerinin sadece mekanik ajitasyon ve solüsyonun hacmine değil ayrıca irrigasyon solüsyonunun kimyasal aktivitesine de bağlı olduğunu rapor etmiştir. $\mathrm{NaOCl}$ dentin debrisinin organik komponentlerini çözmede etkilidir (Baumgartner ve Mader 1987) fakat kalsiyum 
gibi inorganik maddeleri çözmede sınırlı çözme etkinliğine sahiptir (Salgado ve ark 2009). Şelasyon yapan ajanlar $\mathrm{KH}$ 'i uzaklaştırmada $\mathrm{NaOCl}$ den daha etkilidir, EDTA'nın kullanıması kök kanalının temizliğini artırabilmektedir (Salgado ve ark 2009, Rödig ve ark 2010). Bizim çalışmamızda ise $\mathrm{Ca}(\mathrm{OH})_{2}$ patı uzaklaştırıması esnasında yalnızca $\mathrm{NaOCl}$ solüsyonu kullanılmış olup EDTA kullanılmadığı için pat artıkları tamamen uzaklaştıılamamış olabilir. Bizim çalışmamızda irrigasyon solüsyonları değil de kullanılan eğe sistemlerinin KH'nin uzaklaştırımasındaki etkinlikleri değerlendirmek istenmiştir bu nedenle eğeler arasındaki farklar kıyaslanmıştır.

Kök kanallarından KH'nin uzalaştırılmasında rotary enstrümanlarının irrigasyon ile beraber kullanılması önerilmektedir (Kenee ve ark 2006, Kuga ve ark 2010). lyice temizlenmiş kanal duvarlarının başarılması etkili irrigasyona, solüsyonun etkinleștirilmesine ve bütün duvarlara özellikle apical üçlü bölgesine solüsyonun temas ettirilmesine bağlıdır (Gu ve ark 2009, Zehnder 2006). Rotary enstrümanları kök kanalından KH uzaklastırma açısından pasif ultrasonik irrigasyonla benzer etkiler göstermektedir ve yalnızca geleneksel iğne ile irrigasyondan daha fazla $\mathrm{KH}$ uzaklaştırmaktadır. Yalnızca irrigasyon apical üçlüye yeterince penetre olamamaktadır, rotary enstrümanları apical üçlüye ulaşarak daha çok $\mathrm{KH}^{\prime} \mathrm{i}$ uzaklaştırmaktadır (Kenee ve ark 2006). ProTaper ve K3 sistemlerinin $\mathrm{KH}$ 'i uzaklaştırma etkinliklerinin karşılaştııılığı bir çalışmada ProTaper in daha etkili olduğu görülmüştür ve bunun sebebinin ise ProTaper eğelerinin kanal duvarlarına daha iyi adapte olduğundan dolayı olduğu söylenmiştir (Kuga ve ark 2010). Bizim çalışmamız da ise Reciproc eğeleri diğer bütün sistemlerden daha iyi bulunmuştur bunun nedeni de Resiproc eğelerinin resiprokal hareketlerle kullanılmasına ve eğelerin Sşekilli kesitsel şekillerine bağlanabilir.

$\mathrm{Bu}$ çalışmada $\mathrm{KH}$ gliserin ve su karıştııılarak kullanılmıştır. Literatürde karışımın içeriği kök kanallarından artıkların uzaklaştııımasını etkilemediği belirtilmiştir (Lambriniadis ve ark 2009, Balvedi ve ark 2010).

Yapılan bir çalışmada SAF ve ProTaper'in KH uzaklaştırma etkinliğine bakılmış olup sistemlerin ikiside kök kanallarından KH'i tamamen uzaklaştıramamışlardır ve her iki sistem arasında anlamlı bir fark bulunmamıştır (Faria ve ark 2013). Benzer şekilde bu çalışmada da tüm gruplardan kök kanallarında $\mathrm{KH}$ tamamen uzaklaştırılamamıştır. Kenee ve ark (2006) yaptıkları çalışmada ana apikal eğe ve bununla beraber EDTA ve $\mathrm{NaOCl}$ kullanmış olup eğe ile beraber kullanılan irrigasyon solüsyonlarının sadece irrigasyon solüsyonu kullanılan gruplardan daha üstün sonuçlar verdiği görülmüştür. Bizim çalışmamızda da aynı şekilde kontrol grubunda sadece $\mathrm{NaOCl}$ kullanılmış olup bu grupta daha fazla KH artığı kaldığı görülmüştür. Kuga ve ark (2010) yapmış oldukları bir çalışmada ProTaper F1 apikal çapı 25, 0.06, ve K3 apikal çapı 25, 0.06 eğe sistemlerini karşılaştırmış olup $\mathrm{F} 1$ eğesinin daha iyi sonuçlar verdiği gözlenmiştir. Bizim çalışmamızda ise ProTaper Universal F4 apikal çapı 40, ProTaper Next X4 apikal çapı 40, WaveOne Large apical çapı 40 ve R40 eğeleri karşılaştırımış olup R40 eğesinin daha iyi sonuçlar verdiği görülmüştür.

Daha önceden yapılan çalışmalarda da kanallardaki artık KH miktarı skorlama metodu (Van der Sluis ve ark, 2007, Rödig ve ark 2010) taramalı elektron mikroskobu (SEM) (Salgado ve ark 2009, Kuga ve ark 2010), stereomikroskop (Topçuoğlu ve ark 2015) veya CT ile hacimsel analiz (Nandini ve ark 2006) kullanılarak hesaplanmışır. Stereomikroskop ile ölçüm yönteminde dişler longitudinal olarak ikiye ayrılır ve kanalların fotoğrafı çekilerek kalan artık $\mathrm{KH}$ miktarı skorlanarak ölçülür (Tasdemir ve ark 2011). Bizim çalışmamızda da bu yöntem kullanılmıştır. Kenee ve ark (2006) uzunlamasına ayırmanın bütün kanal yüzeyinin ölçümüne daha çok izin vermekte olduğunu rapor etmişlerdir.

Ghobadi ve ark (2012) yapmış oldukları bir çalışmada kök kanallarından KH'i uzaklaştırılmada RaCe ve Mtwo 2 ayrı döner alet sistemini karşılaştırmışır. Tamamen temiz kök kanalları bulunmayıp, Mtwo grubunda daha iyi sonuçlar görülmüş olsa da her iki eğe sistemi arasında istatistiksel bir farklılık bulunmamıştır. Mtwo grubundaki farklılık da eğe sisteminin pozitif rake açısına sahip olduğundan kaynaklandığı düşünülmektedir. K3, ProTaper ve Twisted File In karşılaştıııldığı bir başka çalışmada üç eğe sisteminde arasında anlamlı bir fark bulunmamıştır (Kuga ve ark 2012).

$\mathrm{Bu}$ çalışmada bulunan sonuçlara göre hiçbir eğe sisteminin kök kanalından KH'i tamamen uzaklaştırdığı görülmemiştir, bu sonuç daha önceden yapılan $\mathrm{KH}$ uzaklaştırma teknikleri ile yapılan diğer çalışmalarla desteklenmektedir (Kenee ve ark 2006, Salgado ve ark 2009, Rödig ve ark 2010, 2011).

Kullandığımız döner alet sistemleri içerisinde Resiproc eğelerinin daha üstün sonuçlar verdiği görülmüştür. ProTaper Universal, ProTaper Next, WaveOne ve kontrol grupları arasında istatistiksel olarak anlamlı bir 
fark bulunmamıştır. Reciproc eğelerinin daha üstün sonuçlar göstermesinin nedeni sahip oldukları farklı kesitsel farklılıklar ve kristalografik formları sayesinde daha etkili olabilecekleri düşünülmektedir.

\section{SONUÇ}

$\mathrm{Bu}$ çalışmanın koşulları altında hiçbir eğe sistemi kök kanallarından $\mathrm{KH}$ 'i tamamen uzaklaştıramamıştır. Dört farklı eğe sistemlerinin arasından Reciproc eğelerinin daha fazla temiz kök kanalları sahip olduğu görülmüștür. Reciproc eğe sistemi kök kanallarından KH'i uzaklaştırmada tercih edilebilir.

\section{ÖZET}

\section{Farklı eğe sistemlerinin kök kanallarından kalsiyum hidroksiti uzaklaştırmadaki etkinliklerinin değerlendirilmesi}

Amaç: Tek köklü dişlerden farklı eğe sistemlerini kullanarak kanal içi ilaç olan kalsiyum hidroksit'in $(\mathrm{KH})$ uzaklaştırımasının değerlendirilmesidir.

Gereç ve Yöntemler: Bu çalışmada 30 adet tek köklü çekilmiş insan dişi kullanıldı. Kök kanalları ProTaper F4 eğesine kadar genişletildi. KH patı kök kanallarına çalışma uzunluklarında yerleştirildi. Köklerin koronal kısımlarına pamuk pelet ve geçici bir dolgu maddesi konularak kapatıldı. Daha sonra dişler distile su içinde $37^{\circ} \mathrm{C}$ 'de 7 gün boyunca bekletildi. Sonrasında geçici dolgular kaldırıldı. Kök kanallarındaki KH'ın uzaklaştırılmasında kullanılan yönteme göre örnekler rastgele dört deney grubu (ProTaper Universal F4, ProTaper Next X4, Reciproc 40, WaveOne Large) ve kontrol grubu olmak üzere toplam 5 gruba $(n=12)$ ayrıldı. Kökler bukko-lingual olarak ikiye ayrıldı ve kanal içerisinde kalan artık KH miktarı x 15 büyütmede stereomikroskop altında değerlendirildi. Veriler SPSS programında Cronbach alpha yöntemi ile istatistiksel olarak değerlendirildi.

Bulgular: KH'in kök kanallarından tamamen uzaklaştırılamadığı görüldü. Reciproc eğe sistemi ile istatistiksel olarak diğer gruplardan daha fazla $\mathrm{KH}$ 'i uzaklaştırıldığı belirlendi $(P<0.05)$. Kontrol grubunda diğer gruplardan daha az $\mathrm{KH}$ uzaklaştırımasına rağmen ProTaper Universal, ProTaper Next ve WaveOne eğe sistemleriyle aralarında istatistiksel olarak anlamlı bir fark görülmedi $(P>0.05)$.

Sonuç: Reciproc eğe sisteminin $\mathrm{NaOCl}$ ile birlikte kullanımı kök kanallarından $\mathrm{KH}^{\prime} \mathrm{i}$ uzaklaştırmada yalnızca $\mathrm{NaOCl}$ kullanımından veya ProTaper Universal, ProTaper Next ve WaveOne eğe sistemlerinden daha etkili olduğu görülmüştür. Ancak, kullanılan tekniklerin hiçbiri kök kanallarından $\mathrm{KH}$ 'i tamamen uzaklaştıramamaktadır.

\section{ANAHTAR KELIMELER}

KH'in uzaklaştırılması, ptotaper next, ptotaper universal, resiproc, waveone

\section{KAYNAKLAR}

Amaral P, Forner L, Llena C, 2013. Smear layer removal in canals shaped with reciprocating rotary systems. J Clin Exp Dent, 5, 227-30.

Athanassiadis B, Abbott PV, Walsh LJ, 2007. The use of calcium hydroxide, antibiotics and biocides as antimicrobial medicaments in endodontics. Aust Dent J, 52, 64-82.

Ayna B, Ayna E, Celenk S, 2010. Endodontic and prosthetic treatment of teeth with periapical lesions in a 16 year-old-girl. J Appl Oral Sci, 18, 201-6.

Balvedi RP, Versiani MA, Manna FF, Biffi JC, 2010. A comparison of two techniques fort he removal of calcium hydroxide from root canals. Int End J, 43, 763-8.

Barbizam JV, Trope M, Teixeira EC, Tanumaru- Filho M, Teixeira FB, 2008. Effect of calcium hydroxide intracanal dressing on the bond strength of a resin-based endodontic sealer. Brazilian Dental J, 19, 224-7.

Baumgartner JC, Mader CL, 1987. A scanning electronic microscopic evaluation of four root canal irrigation regimens. J Endod, 13, 147-57.

Bürklein S, Hinschitza K, Dammaschke T, Schafer E, 2012. Shaping ability and cleaning effectiveness of two single-file systems in severely curved root canals of extracted teeth: Resiproc and WaveOne versus Mtwo and ProTaper. Int Endod J, 45, 449-461.

Bystrom A, Sundqvist G, 1981. Bacteriologic evaluation of the efficacy of mechanical rootcanal instrumentation in endodontic therapy. Scand J Dent Res, 89, 321-8.

Bystrom A, Claesson R, Sundqvist G, 1985. The antibacterial effect of camphorated paramonochlorophenol, camphorated phenol and calcium hydroxide in the treatment of infected root canals. Endod Dent Traumatol, 1, 170-5.

Calıskan MK, Turkun M, Turkun LS, 1988. Effect of calcium hydroxide as an intracanal dressing on apical leakage. Int Endod J, 31, 173-7.

Calt S, Serper A, 1999. Dentinal tubule penetration of root canal sealers after root canal dressing with calcium hydroxide. J Endod, 25, 431-3. 
Cohen S, Burns RC, 2010. Pathways of the pulps 10th edition, p.299-302.

Faria G, Nelson-Filho P, Freitas AC, Assed S, Ito IY, 2005. Antibacterial effect of root canal preparation and calcium hydroxide paste (Calen )intracanal dressing in primary teeth with apical periodontitis. J Appl Oral Sci, 13, 351-5.

Faria G, Silva RA, Flori-Junior M, Nelson-Filho P, 2004. Re-eruption of traumatically intruded mature permanent incisor: case resport. Dent Traumatol, 20, 229-32.

Faria G, Kuga MC, Ruy AC, Aranda-Garcia AJ, BonettiFilho I, Guerreiro-Tanomaru JM, 2013. The efficacy of the self-adjusting file and ProTaper for removal of calcium hydroxide from root canals. J Appl Oral Sci, 21, 346-50.

Fava LR, Saunders WP, 1999. Calcium hydroxide pastes: classifications and clinical indications. Int End J, 32, 257-82.

Ghobadi M, Dadresanfar B, Raoof HR, Abbas FM, 2012. Removal of intracanal calcium hydroxide paste with two rotary systems: RaCe and Mtwo. Dental Press Endod, 2, 23-7.

Grecca FS, Leonardo MR, Silva LAB, 2001. Radiographic evaluation of periradicular repair after endodontic treatment of dog's teeth with induced periradicular periodontitis. J Endod, 27, 610-2.

Gu LS, Kim JR, Ling J, Choi KK, Pashley DH, Tay FR. Review of contemporary irrigant agitation techniques and devices. J Endod 2009; 35: 791-804.

Hulsmann M, Peters O, Dummer P, 2005. Mechanical preparation of root canals: shaping goals, techniques and means. Endod Topics, 10, 30-76.

Johnson E, Lloyd A, Kuttler S, Namerow K. Comparison between a novel nickel titanium alloy and 508 Nitinol on the cyclic fatigue life of Profile 25/.04 rotary instruments. J Endod 2008;34: 1406-9.

Kenee DM, Allemang JD, Johnson JD, Hellstein J, Nichol BK, 2006. A quantitative assessment of efficiacy of various calcium hydroxide removal techniques. $J$ Endod, 32, 563-5.

Kim SK, Kim YO, 2002. Influence of calcium hydroxide intracanal medication on apical seal. Int Endod J, 35, 623-8.

Kuga MC, Tanomaru-Filho M, Faria G, So MV, Galletti T, Bavello JR, 2010. Calcium hydroxide dressing removal with different rotary instruments and irrigating solutions: a scanning electron microscopy study. Braz Dent J, 21, 310-4.
Kuga MC, Campos EA, Faria-Junior NB, Só MVR, Shinohara AL, 2012. Efficacy of NiTi rotary instruments in removing calcium hydroxide dressing residues from root canal walls. Braz Oral Rez, 26, 19-23.

Lambrianidis T, Margelos J, Beltes P, 1999. Removal efficiacy of calcium hydroxide dressing from the root canal. J Endod, 25, 85-8.

Lambrianidis T, Kosti E, Boutsioukis C, Mazinis M, 2006. Removal efficacy of various calcium hydroxide/chlorexidine medicaments from the root canal. Int End J, 39, 55-61.

Lee M, Winkler J, Hartwell G, Stewart J, Caine R, 2009. Current trends in endodontic practice: emergency treatment and technological armamentarium. J Endod, 35, 35-9.

Lee SJ, Wu MK, Wesselink PR, 2004. The effectiveness of syringe irrigation and ultrasonics to remove debris from simulated irregularities within prepared root canal walls. Int Endod J, 37, 672-8.

Margelos J, elidas G, Vardelis C, Palaghias G, 1997. Interaction of calcium hydroxide with zinc oxide eugenol type sealers: a potential clinical problem. J Endod, 23, 43-8.

Meire M, De Moor R, 2008. Mineral trioxide aggregate repair of a perforating internal resorption in a mandibular molar. J Endod, 34, 220-3.

Mohammadi Z, Dummer PM, 2011. Properties and applications of calcium hydroxide in endodontics and dental traumatology. Int Endod J, 44, 697730 .

Nandini S, Velmurugan N, Kandaswamy D. 2006. Removal efficiency of calcium hydroxide intracanal medicament with two calcium chelators: volumetric analysis using spiral $\mathrm{CT}$, an in vitro study. J Endod, 32, 1097-101.

ProTaper Next Brochure. Dentsply 2013.

Ricucci D, Siqueira JF Jr, 2008a. Anatomic and microbiologic challenges to achieving success with endodontic treatment: a case report. J Endod, 34,1249-54.

Ricucci D, Siqueira JF Jr, 2008b. Apical actinomycosis as a continuum of intraradicular and extraradicular infection: case report and critical review on its involvement with treatment failure. J Endod, 34, 1124-9. 
Ricucci D, Langeland K, 1997. Incomplete calcium hydroxide removal from the root canal: a case report. Int Endod J, 30, 418-1.

Rödig T, Vogel S, Zapf A, Hülsmann M, 2010. Efficacy of different irrigants in the removal of calcium hydroxide from root canals. Int Endod J, 43, 519-27.

Rödig T, Hirschleb M, Zapf A, Hülsmann M. Comparison of ultrasonic irrigation and RinsEndo for the removal of calcium hydroxide and Ledermix paste from root canals. Int Endod J. 2011; 44: 1155-61.

Ruddle CJ. The ProTaper advantage: shaping the future of endodontics. Dentistry Today Oct 2001, 1-9.

Salgado RJ, Moura-Netto C, Yamazaki AK, Cardoso LN, De Moura AA, Prokopowitsch I, 2009. Comparison of different irrigants on calcium hydroxide medication removal: microscopic cleanliness evaluation. Oral Surg Oral Med, Oral PAth, Oral Radio and Endod, 107, 5804.

Siqueira LF, Lopes HP, 1999. Mechanisms of antimicrobial activity of calcium hydroxide: a critical review. Int Endod J, 32, 361-9.

Tanomaru-Filho M, Leonardo MR, Silva LAB, 2002. Effect of irrigation solution and calcium hydroxide root canal dressing on the repair of apical and periapical tissues of teeth with periapical lesion. J Endod, 28, 295-9.

Topçuoğlu H.S, Düzgün S, Ceyhanlı K.T, Aktı A, Pala K, Kesim B, 2015. Efficacy of different irrigation techniques in the removal of calcium hydroxide from a simulated internal root resorption cavity. Int Endod J, 48, 309-316.

Van derSluis LW, Wu MK, Wesselink PR, 2007. The evaluation of removal of calcium hydroxide paste from an artificial standardized groove in the apical root canal using different irrigation methodologies. Int Endod J, 40, 52-7.

Vaudt et al. Evaluation of rotary root canal instruments in vitro: a review. ENDO 2007;1: 189-203.

Wiseman A, Cox TC, Paranjipe A, Flake NM, Cohenca $\mathrm{N}$, Johnson JD, 2011. Efficacy of sonic and ultrasonic activation for removal of calcium hydroxide from mesial canals of mandibular molars: a microtomographic study. J Endod, 37, 235-8.

Webber J, Machtou P, Kuttler S, Ruddle C, West J, 2011. The Wave One single file resiprocating system. Roots, 1, 28-33.
You SY, Bae KS, Baek SH, Kum KY, Shon WJ, Lee W, 2010. Lifespan of one nickel-titanium rotary file with reciprocating motion in curved root canals. J Endod, 36, 1991-4.

Zehnder M. Root canal irrigants. J Endod 2006;32:389-98.

Yazışma Adresi:

Dt.Selen INCE YUSUFOĞLU

Selçuk Üniversitesi

Diş Hekimliği Fakültesi Endodonti AD

42075 Selçuklu, Konya

Tel: +903322231237

Tel: +90 5376833095

E-mail: dtselenince@hotmail.com 